\title{
Rates of production of methane in the rumen and large intestine of sheep
}

\author{
By R. M. MURRAY*, A. M. BRYANT† AND R. A. LENG \\ Department of Biochemistry and Nutrition, School of Rural Science, \\ University of New England, Armidale, New South Wales 2351, Australia
}

(Received 8 April I975-Accepted I December 1975)

\begin{abstract}
1. An isotope tracer method for estimating methane production in sheep is described.
2. The technique was used to estimate methane produced in both the upper and lower digestive tract and to determine the routes by which it was excreted.

3. Four Merino ewes given lucerne chaff ( $33 \mathrm{~g}$ every hour) were used.

4. Total methane production rate was $2 I \pm X \cdot 1(\mathrm{SE}) \mathrm{ml} / \mathrm{min}$; production in the rumen accounted for $87 \pm 1 \cdot 2 \%$ of the total production; $95 \pm 1.4 \%$ of the methane produced in the rumen was excreted by eructation.

5. Of the methane produced in the lower digestive tract, $89 \pm 2.3 \%$ was excreted through the lungs and II \% through the anus.
\end{abstract}

In ruminants, digestion in the rumen appears to account for a large proportion of the total digestion of foods (Baldwin, Lucas \& Cabrera, I970) and therefore an estimate of fermentation rate in the rumen gives a considerable amount of information about the nutritive value of a particular diet or ration. There are two general procedures for obtaining quantitative measures of this digestion. One procedure relies on measuring the rate of production or absorption of one or more fermentation end-products (Leng \& Murray, 1972), the other relies on monitoring the amount and composition of digesta passing the duodenum (e.g. Hogan \& Weston, r970).

In the past few years fermentation rate has been estimated by isotope dilution techniques using ${ }^{14} \mathrm{C}$ - or ${ }^{3} \mathrm{H}$-labelled acetate or mixtures of volatile fatty acids (VFA) (Leng \& Leonard, I965; Grey, Weller, Pilgrim \& Jones, I966; Weston \& Hogan, I 968 ). As emphasized by Leng (1974), the precision of the technique is low, a serious disadvantage if stoichiometric principles (Hungate, I966) are to be used to calculate the extent of digestion and microbial cell synthesis from the measured VFA production rates. The major problem here is that associated with the mixing into the rumen pool of the labelled acids administered. In contrast, mixing may be more rapid and complete within the gaseous phase and therefore an isotope technique for measuring methane production may not suffer these disadvantages.

In addition to a requirement for a more accurate measure of rumen fermentation we needed a technique to continuously monitor methane production in the rumen and lower digestive tract in unrestrained animals, which could be applied to a number of animals simultaneously. The isotope dilution technique described here met some of these requirements. The basis of the technique is that if radioactively labelled methane is infused into the animal in such a way as to mix with the methane in solution in the

* Present address: Department of Tropical Veterinary Science, James Cook University, Townsville, Queensland 481 1, Australia.

† Present address: Ruakura Agricultural Research Centre, Hamilton, New Zealand. 
rumen fluid, then after equilibration the specific radioactivity (SR) of methane in the gas phase (which is directly derived from the pool in solution) would indicate the rate of production of methane in the rumen. The difference between that produced in the animal (as assessed by total collection) and that produced in the rumen indicates methane produced in the lower digestive tract. Preliminary studies indicated that methane produced in the lower digestive tract was largely absorbed and excreted through the lungs and therefore the SR of methane in rumen gas and expired gas indicates the production in the rumen and approximates that produced in the animal respectively.

\section{EXPERI MENTAL}

\section{Animals and diet}

Four adult Merino ewes with rumen fistulas and weighing approximately $35 \mathrm{~kg}$ were used. Two of the animals also had caecum fistulas inserted $30 \mathrm{~mm}$ from the blind end. The animals were kept in metabolism cages and given $800 \mathrm{~g}$ lucerne chaff/d from an automatic feeder which dispensed an equal portion of the ration each hour.

The animals had been accustomed to the experimental procedures for at least I year before this experiment and were on a continuous feeding regimen for at least 3 weeks before measurements began.

\section{Equipment}

A diagram of the gas collection and analysis apparatus is shown in Fig. I.

Sampling. Room air was drawn into a fibreglass mask (see p. 6), and across the muzzle of the animal by a centrifugal pump capable of moving $60 \mathrm{l} / \mathrm{min}$ (see Fig. $\mathrm{r}$ ). From the mask, the gas was drawn serially through a $3 \mathrm{~m}$ length of flexible polyvinyl chloride tubing of $50 \mathrm{~mm}$ i.d., a 21 container containing glass-wool to remove large particulate matter, a gas meter to measure total flow, the centrifugal pump, and then to the atmosphere. A subsample was drawn from the main stream for analysis of gas content and radioactivity.

The total-flow gas meter was a Smith reciprocating-piston displacement meter of the dry type, assembled by Gas Meters Pty Ltd, Sydney, Australia. Its capacity was $40001 / \mathrm{h}$ with a stated accuracy of $\pm 0.5 \%$, and it metered $201 / \mathrm{rev}$.

Subsampling. A subsample of the collected gas was drawn off after the total-flow gas meter (see Fig. I) by a positive-pressure piston pump (Elnor 25oR; Air-Shields (UK) Ltd, Southend-on-Sea, Essex, UK) capable of pumping $101 / \mathrm{min}$. A needle valve controlled the amount of gas passing to the analysers. Copper tubing ( $5 \mathrm{~mm}$ i.d.) was used in this part of the instrument. All permanent connexions were soldered, and temporary joints were made with ground-glass fittings enclosed in rubber pressure tubing.

From the piston pump, the gas passed either direct to the analysers through a calcium chloride drying train or through a degassing complex used in the analysis of radioactivity in the infusate solution. Standards of unknown gas samples were introduced from syringes through the injection port. A small $100 \mathrm{ml}$ trap containing glasswool was included after the drying trains to prevent contamination of the analysers with dust. 


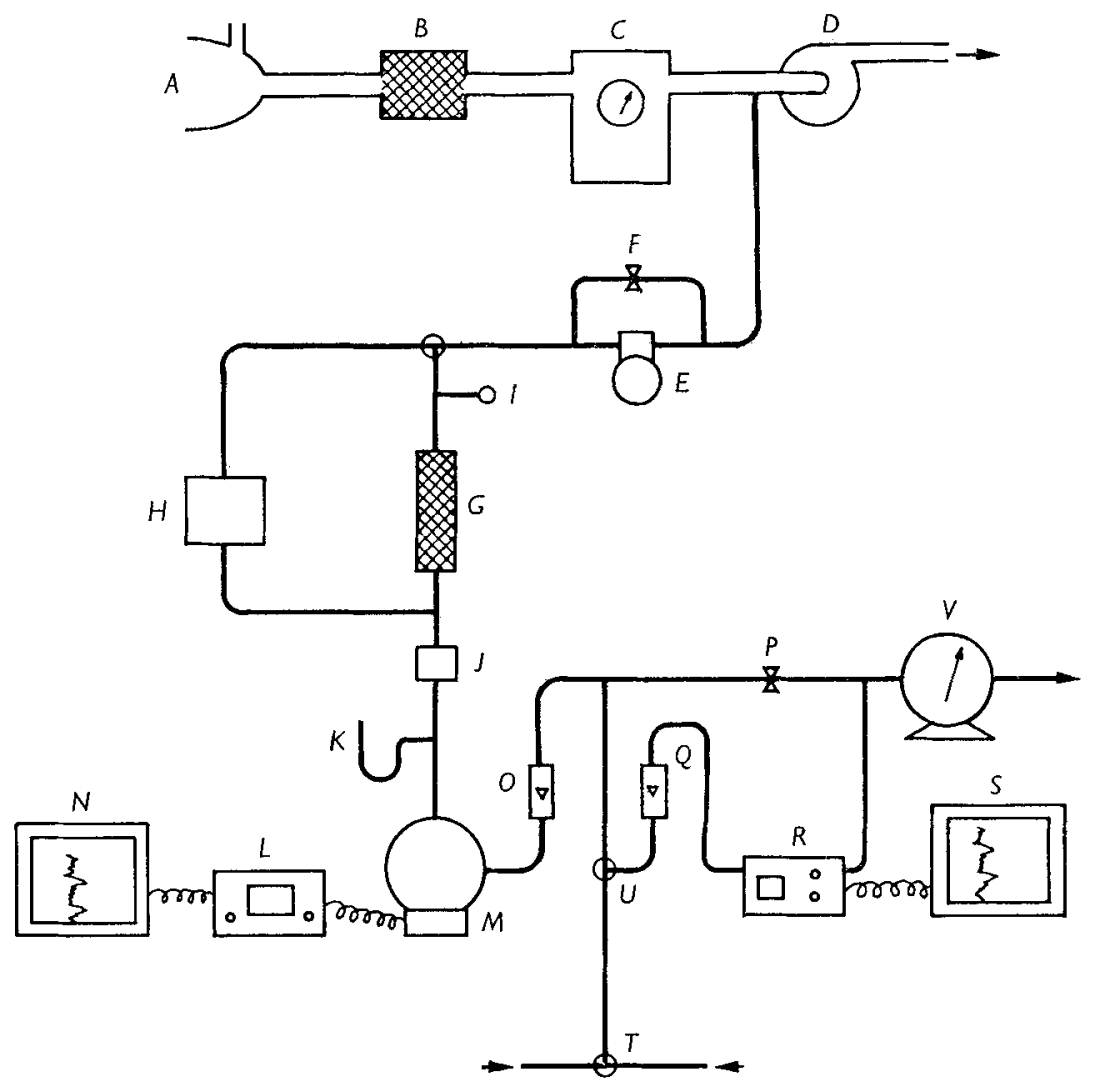

Fig. I. Apparatus used for collection of gases from a sheep and determination of methane content and specific radioactivity. $A$, fibreglass face-mask; $B$, trap containing glass-wool; $C$, gas meter; $D$, centrifugal pump; $E$, positive-pressure piston pump; $F$, needle valve; $G$, calcium chloride drying train; $H$, degassing apparatus (see Fig. 3 ); $I$, injection port; $\mathcal{F}$, glasswool dust-trap; $K$, mercury manometer; $L$, vibrating-reed electrometer; $M$, ion chamber; $N$, strip chart recorder; $O$, variable-aperture flow-meter; $P$, by-pass needle valve; $Q$, variableaperture flow-meter; $R$, infrared methane analyser; $S$, strip chart recorder; $T, U$, inlet taps; $V$, wet gas meter. For detailed description of apparatus see pp. $2-4$.

A mercury manometer was used to measure the atmosphere pressure in the subsampling train.

Radioactivity in the gases was determined in a 4.31 ion chamber attached to a Carey 3I vibrating-reed electrometer (Applied Physics Corporation, Monrovia, California, USA). The ion-chamber response was recorded on a Speedomax W strip chart recorder (Leeds \& Northrup Co., Philadelphia, Pennsylvania, USA). All the subsampled gas was drawn through the ion chamber, which acted as a mixing vessel, with the flow being indicated by a Gap Meter variable-aperture flow-meter (Duff \& MacIntosh Ltd, Sydney, Australia), and calibrated for air-flows from 200 to $4000 \mathrm{ml} /$ min.

The content of methane in the gas leaving the ion chamber was estimated with an infrared analyser (Lira Model 300; Mine Safety Appliances Co., Pittsburg, 
Pennsylvania, USA). Flow of gas through this analyser was maintained at $\mathrm{r} \cdot 01 / \mathrm{min}$ with the aid of a by-pass needle valve, and a second Gap Meter calibrated from Ioo to $1200 \mathrm{ml} / \mathrm{min}$. The analyser output of $0-100 \mathrm{mV}$ was modified to the $0-5 \mathrm{mV}$ input of the Brown Electronick strip chart recorder (Honeywell Controls Ltd, Industrial Instruments, Newhouse, Motherwell, Lanarkshire, UK). The methane analyser was calibrated daily using gases of known methane concentrations introduced through a series of taps placed before the second Gap Meter.

The two streams of the subsampled gas were recombined after the methane analyser and passed through a wet gas meter (Alexander Wright \& Co. Ltd, London, UK). This meter had a maximum capacity of $101 / \mathrm{min}$, a stated accuracy of $\pm 0.25 \%$ over its entire range, and it metered $2.51 / \mathrm{rev}$.

\section{Calibration of the instruments}

The 'face-value' readings of all the instruments were checked and, where necessary, correction factors obtained.

Smith gas meter. The Smith gas meter was periodically calibrated against a test meter. This was also a Smith gas meter and was calibrated by expanding oxygen (Medical grade; Commonwealth Industrial Gases, Sydney, Australia) through the meter at six flow-rates in the range $20-501 / \mathrm{min}$. The weight of $\mathrm{O}_{2}$ used at each flowrate (200-300 g) was determined.

Wright gas meter. Calibration was by air displacement with water using flow-rates over the range of $800-3200 \mathrm{ml} / \mathrm{min}$. The volume of gas which passed through the meter was calculated from the weight of water used to displace the gas.

Electrometer and ion chamber. The linearity of response over the instrument's complete range was established by applying known voltage inputs into the electrometer. The voltage potential across the ion chamber which resulted in maximum response to a given power input was $9 \circ \mathrm{V}$, which was supplied by dry-cell batteries. With the instrument checked for maximum output, it was calibrated for response to known quantities of radioactivity from both tritium gas and ${ }^{14} \mathrm{CO}_{2}$.

Methane analyser. The instrument was only used within the $0-0.2 \%$ range, and the calibration for this range was checked by the use of six standard gas mixtures purchased from Commonwealth Industrial Gases. The compositions of these gas mixtures were within the stated range when checked using a Haldane apparatus. These gas mixtures were used each day to set the span adjustment of the instrument. Nitrogen gas was used to zero the analyser.

\section{Experimental procedures}

Preparation of infusion solutions. ${ }^{14} \mathrm{C}$ - and ${ }^{3} \mathrm{H}$-labelled methane gas was purchased from the Radiochemical Centre, Amersham, Bucks., UK.

Special equipment had to be developed to handle the gas, which had a high SR. To prevent losses by diffusion, glass and metal were used throughout except where joints were necessary, then multiple butyl-rubber seals were used. The apparatus consisted of a vial breaker which fitted into a 21 flask. The vial breaker (Fig. 2), with 


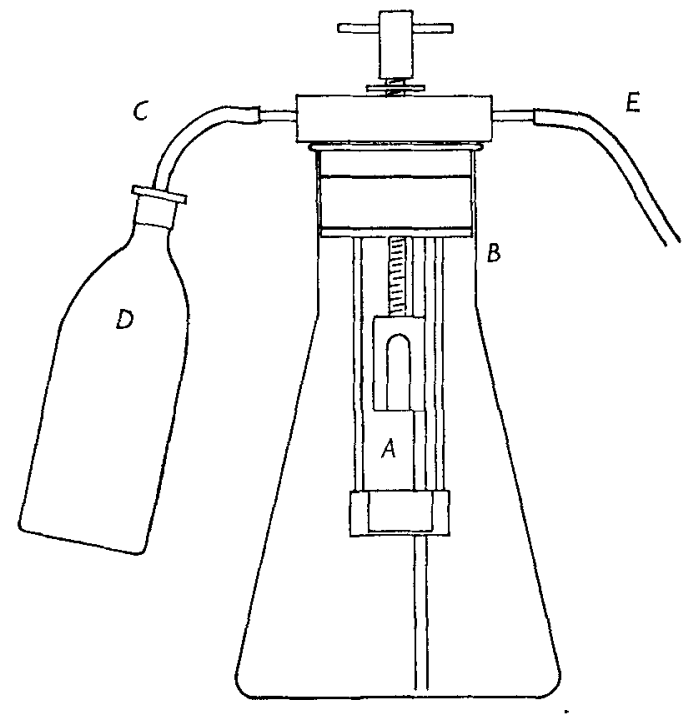

Fig. 2. Apparatus used to transfer radioactive methane gas to the infusion solution, $A$, vial breaker; $B$, sealed 2 l flask; $C$, outlet tube; $D$, collapsible plastic bottle; $E$, outlet tube. For detailed description of apparatus, see pp. 4-5.

a vial in place, was introduced into a 21 glass flask connected through one of the outlet tubes to a collapsible bottle. Both the flask and the bottle were filled with distilled water while it was still hot after degassing by boiling for 20-30 min. All pockets of air were expelled through the second outlet which was then sealed. The entire system was allowed to cool, water moving into the flask from the collapsible container. The vial was then crushed and, with shaking, complete solution was obtained in 3-6 $\mathrm{h}$. This solution was then transferred to $500 \mathrm{ml}$ glass flasks and sealed until required. There was no loss of radioactivity from these containers during storage for 8 weeks.

Calibration of infusate. Infusion solutions were assayed in the same system as normal gas samples. In order to release the methane from solution it was necessary to heat this and remove the water. The system (Fig. 3) consisted of a stainless-steel degassing tube held in a sand-bath heated by an electric element. Weighed amounts of infusate (approximately $\mathrm{I} g$ ) were injected into the degasser through the injection port in the rubber bung, and washed in with $2 \mathrm{ml}$ water. Air entering through a pipe flushed the steam and radioactive gases into a condenser, through a $\mathrm{CaCl}_{2}$ drying train (not shown in Fig. 3) and then through the ion chamber (see Fig. I) of the analysis apparatus. The temperature of the sand-bath was maintained at $120-200^{\circ}$, since lower temperatures resulted in incomplete release of radioactivity, and higher temperatures resulted in loss of radioactivity presumably through oxidation.

Method of infusing radioactive methane into sheep. An all-metal system was used. The infusate was pumped from a $350 \mathrm{ml}$ gas-tight metal syringe at $\mathrm{O} \cdot \mathrm{x} \mathrm{ml} / \mathrm{min}$ by a Palmer slow injection pump (C. F. Palmer Ltd, London, UK) through Cu tubing (I mm i.d.). Infusion rates of $0.1,0.7,1 \cdot 2$ and $2 \cdot 4 \mathrm{ml} / \mathrm{min}$ were achieved by maintaining a constant infusion by the Palmer pump but having a variable input of water through a ' $\mathrm{Y}$ ' 


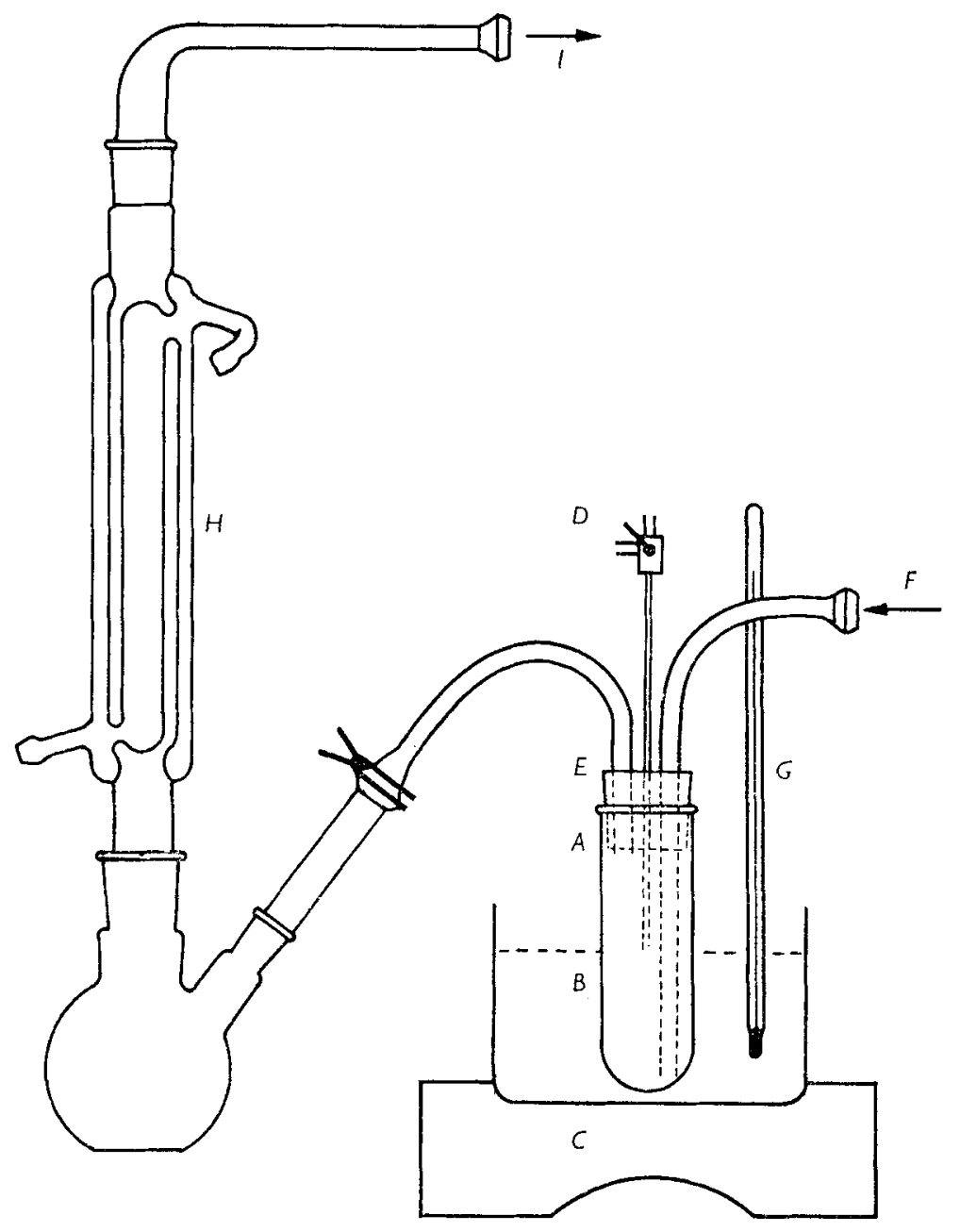

Fig. 3. Apparatus used to liberate methane from solution before determination of radioactivity. $A$, stainless-steel degassing tube; $B$, sand-bath; $C$, electric element; $D$, injection port; $E$, rubber bung; $F$, inlet from subsample system pump, providing air-flow to flush sample through apparatus; $G, 0-300^{\circ}$ thermometer; $H$, water-cooled condenser; $I$, outlet to ion chamber through a drying train. For detailed description of apparatus, see p. 5.

junction in the line using a peristaltic pump. Infusions were made at rates of 0.5 and $\mathrm{x} \cdot 5 \mu \mathrm{Ci} / \mathrm{min}$ for ${ }^{14} \mathrm{C}$ and ${ }^{3} \mathrm{H}$-labelled methane respectively. Intraruminal infusions were made for periods of up to $48 \mathrm{~h}$ while those into the caecum were of $24 \mathrm{~h}$ duration.

Collection of respired and eructated gases. During infusion experiments gases from the head were collected between each hourly feed by using a fibreglass mask fitted over the muzzle of the sheep, and sealed with foam rubber around the face. Room air was drawn through the mask as described previously. A $500 \mathrm{~mm}$ flexible tube was incorporated on the inlet side of the mask to prevent respired gases being lost during forced expiration.

Collection of gas passed through the anus. Use was made of the faecal collection 
apparatus and harness described by Royal (1968). The rubber sleeve which surrounded the anus was lined with a Perspex tube having an outlet in one side. During collection of flatus the $3 \mathrm{~m}$ air-line from the centrifugal pump was fitted to this outlet instead of to the face-mask. The faeces collection bag was replaced with an open-ended plastic bag allowing exit of faeces and urine and entry of air.

Sampling of rumen gas. Gas-tight syringes were used to collect gas through a stainless-steel tube connected to a gauze cage made of stainless-steel wire held in the gas space of the dorsal region of the rumen. Nylon stocking mesh over the gauze cage prevented plant materials from blocking the sampling tube. Methane SR was estimated hourly on a composite of six $5 \mathrm{ml}$ samples collected every ro min.

Gas dissolved in urine. Urine was collected towards the end of the $48 \mathrm{~h}$ intraruminal infusions of $\left[{ }^{3} \mathrm{H}\right]$ methane; $10 \mathrm{ml}$ was immediately degassed (see p. 5 ) and the gases analysed for radioactivity and methane content.

Recovery of infused isotope. During the study of the extent of recovery of the infused isotope the face-mask was replaced by a Perspex hood which was to collect gases during feeding. The hood was attached to the animal by a plastic curtain which was tied closely around its neck. An air-lock was provided to permit feeding of the animal, and thus allow continuous sampling of gases during feeding. Room air was drawn across the rumen fistula and thence through the hood to the sampling system so that there was no possibility of loss of any methane. The hood was used for total collection of gases from the head, from $3-8 \mathrm{~h}$ after the start of infusion. The animal was given food manually during these periods.

\section{Interpretation of analyser response}

Respired gases. When sheep were fed every hour, the respired gases were collected for $45 \mathrm{~min}$ during each period, allowing $15 \mathrm{~min}$ for the animal to consume its meal, and during this time each analyser returned to background readings. The output signals from both the infrared analyser and vibrating-reed electrometer were recorded continuously. The total radioactivity and methane in the gases during this time was estimated from the area under these curves as measured with a planimeter. Calibration curves had been previously constructed. The SR of the 'mask' gas was calculated as $\mu \mathrm{Ci} / \mathrm{ml}$ methane.

Rumen gas. Rumen gas samples (10-20 ml), collected as described previously, were injected into the subsampling line through the injection port (see Fig. 1). A rapid response was followed by a slow, exponential decay.

The ion chamber's response was a mono-exponential decay in which the slope of the $\log$ decay curve was dependent only on the flow of the subsample stream. The product $\left(K_{r}\right)$ of this flow and the area under the response curve (as measured by the planimeter) was related linearly to the amount of radioactivity injected by the equations:

and

$$
\begin{aligned}
& Y_{T}=1.38( \pm 0.015) K_{r} \\
& Y_{C}=0.17( \pm 0.002) K_{r},
\end{aligned}
$$

where $Y_{T}$ is $\mu \mathrm{Ci}\left[{ }^{3} \mathrm{H}\right]$ methane injected over the range o-10o $\mu \mathrm{Ci}$ and $Y_{C}$ is $\mu \mathrm{Ci}$ 
$\left[{ }^{14} \mathrm{C}\right]$ methane injected over the range $0-20 \mu \mathrm{Ci}$. The values in parentheses represent the sEs of the regression coefficients.

In contrast, the output from the methane analyser was not linear, being dependent not only on the rate of gas-flow through the analyser but also on the non-linear response of the instrument. The relationship between the actual quantity of methane injected $\left(Y_{m}, \mathrm{ml}\right)$ and the product $\left(K_{m}\right)$ of the flow and the area under the response curve (as measured by the planimeter) was significantly quadratic $(P<0.01)$. This relationship, established over the range of $0-10 \mathrm{ml}$ methane (SES of the regression coefficients in parentheses) was found to be:

$$
Y_{m}={ }_{1582}( \pm 30) K_{m}+0.30( \pm 0.07) K_{m}{ }^{2} .
$$

Flatus. Irrespective of whether flatus release was as a series of small emissions during defaecation or as a single large emission, the amount of methane released was validly estimated using the relationships described for single injections of rumen gas.

\section{Calculations}

Methane production in the rumen $\left(\mathrm{M}_{\mathrm{R}}, m l / m i n\right) . M_{R}$ was calculated from the SR of methane in rumen gases $\left(\mathrm{SR}_{R}, \mu \mathrm{Ci} / \mathrm{ml}\right)$ and the infusion rate of radioactivity $(I, \mu \mathrm{Ci} / \mathrm{min})$ as:

$$
M_{R}=I / \mathrm{SR}_{R} .
$$

Methane production in the lower digestive tract $\left(\mathrm{M}_{\mathrm{L}}, \mathrm{ml} / \mathrm{min}\right)$. When labelled methane is infused into the rumen, all the radioactivity at the mask must come from the rumen. If some unlabelled methane at the mask comes from the lower digestive tract then the SR of this methane will be lower than the SR of methane in the rumen. Suppose that the plateau SR of methane at the mask is $\mathrm{SR}_{H}(\mu \mathrm{Ci} / \mathrm{ml})$ then,

$$
M_{H}=I / \mathrm{SR}_{H},
$$

where $M_{H}$ is the total methane collected from the head.

The methane produced in the lower digestive tract $\left(M_{L}\right)$ is partly excreted in flatus $\left(M_{L F}\right)$ and partly through the lungs and breath $\left(M_{L H}\right)$, and therefore,

$$
M_{L}=M_{L H}+M_{L F^{*}}
$$

But $M_{L H}=M_{H}-M_{R}$ and therefore the total methane production in the lower digestive tract can be calculated:

$$
M_{L}=M_{H}-M_{R}+M_{L F} .
$$

Proportion of methane produced in the rumen that is absorbed and excreted through the lungs $(\mathrm{P})$. If the radioactivity excreted at the mouth when eructation was prevented by allowing rumen gas to escape through an open cannula is $I_{P}(\mu \mathrm{Ci} / \mathrm{min})$, then $P$ can be obtained as follows:

$$
P=I_{P} / I
$$


Table I. Rate of excretion and specific radioactivity $(S R)$ of methane, and recovery of labelled methane isotope $\left({ }^{3} \mathrm{H}\right.$ - or ${ }^{14} \mathrm{C}$-labelled) infused into the rumen of sheep, when expired gases were collected from the hood around the head of the sheep

(Determinations were made over $6 \mathrm{~h}$ using two sheep fed hourly; each hourly period was divided into two $30 \mathrm{~min}$ periods, one began and the other ended with feeding)

$\begin{array}{cccc}\text { Collection period } & \begin{array}{c}\text { Excretion } \\ (\mathrm{ml} / \mathrm{min})\end{array} & \begin{array}{c}\mathrm{SR} \\ (\mathrm{nCi} / \mathrm{ml})\end{array} & \begin{array}{c}\text { Infused isotope } \\ \text { recovered }(\%)\end{array} \\ 0-30 \mathrm{~min} & 17 \cdot 3 & 98 & 96 \\ \text { 30-60 min } & 15.6 & 97 & 86 \\ \text { Difference } & \mathrm{I} \cdot 7 & \mathrm{I} \cdot 0 & 10 \\ \mathrm{SE} & 0.6 & \mathrm{r} \cdot 0 & 3.3\end{array}$

Table 2. Rate of methane production in the rumen and lower digestive tract of sheep given infusions of labelled methane into the rumen

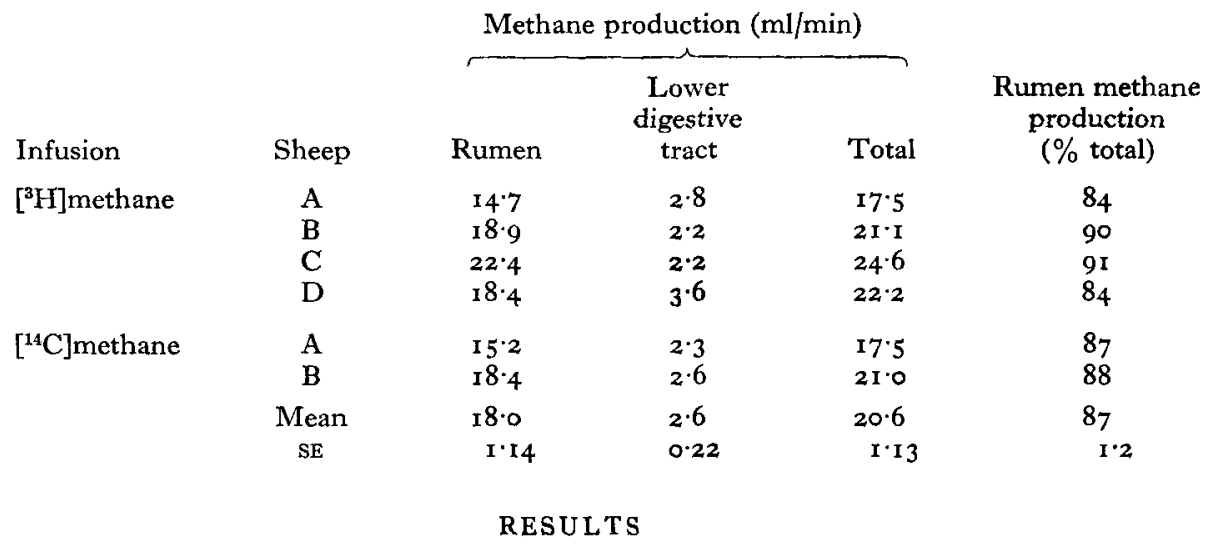

Optimum infusion rate. The ratio, SR of methane in rumen gas:SR of methane in 'mask' gas increased as the volume rate of infusion was increased from 0.12 to $\mathrm{I} \cdot \mathrm{O} \mathrm{ml} / \mathrm{min}$. At higher infusion rates $(\mathrm{r} \cdot 0-2 \cdot 4 \mathrm{ml} / \mathrm{min})$ the ratio remained constant; infusion rates of $\mathrm{I} \cdot 2 \mathrm{ml} / \mathrm{min}$ were used in all subsequent experiments.

Recovery of infused isotope. In order to determine the rate of excretion of infused radioactivity, the sheep's head was enclosed in a hood. The large pool size of the hood $(\mathrm{r} 5 \mathrm{O})$ resulted in slow mixing of the excreted methane, and therefore a slow response to any output by the animal. To overcome this delayed response, each hourly feeding period was divided into two 30 min periods, one beginning and the other ending with the start of feeding. The pooled results indicated that significantly $(P<0.01)$ more methane was collected during feeding than during the $30 \mathrm{~min}$ before feeding, even though there was no change in SR. The results, together with values for recovery of isotope, are given in Table $\mathrm{I}$.

Variation in plateau $S R$ of methane in the rumen gas. The SR of the methane from the rumen was found to reach its maximum value by $4 \mathrm{~h}$ after the start of infusion. The plateau SR remained remarkably constant after this period and during the hourly intervals between 4 and $8 \mathrm{~h}$ of infusion, the coefficient of variation was $\mathrm{r} \cdot 6$.

Methane production in the rumen. Production rates of methane in the rumen were 
IO

R. M. Murray, A. M. Bryant and R. A. Leng

$197^{6}$

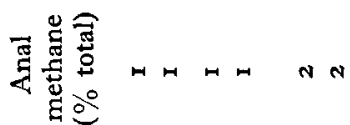

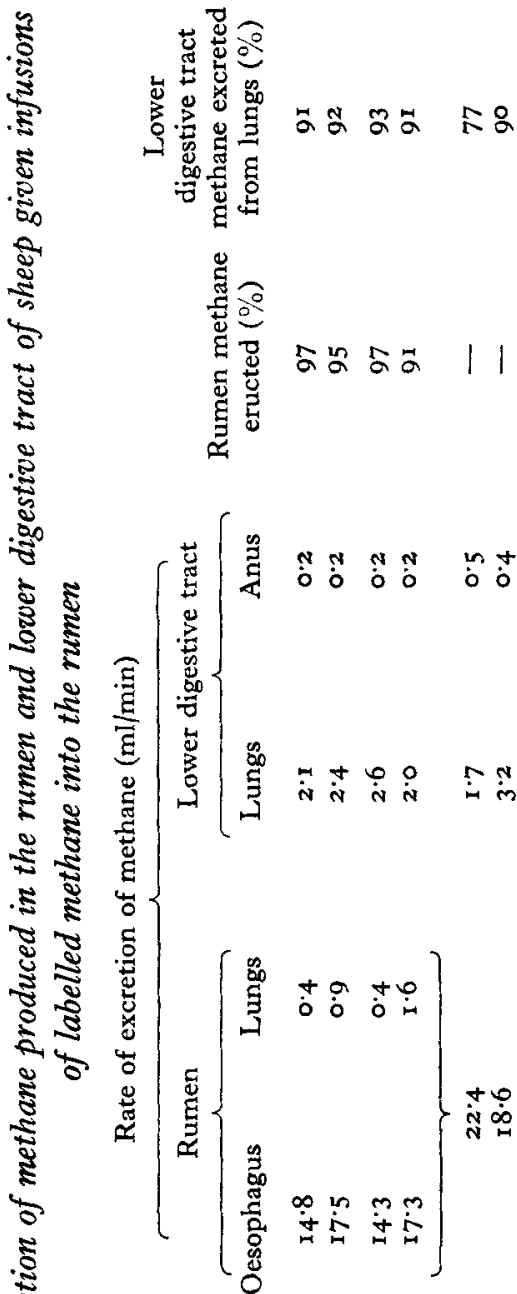

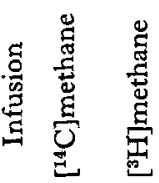

怤《のてのU口 
measured in two animals, using $\left[{ }^{14} \mathrm{C}\right]$ - and $\left[{ }^{3} \mathrm{H}\right]$ methane infusions (see Table 2 ). There was no significant difference in the estimates made using the two isotopes.

Methane production in the hind gut. Methane was absorbed from the hind gut into the portal blood and excreted through the lungs. This was indicated by the appearance of radioactivity in gas from the mask within $5^{-1} 5$ min from the start of intracaecal infusion of $\left[{ }^{3} \mathrm{H}\right]$ methane. The proportion of the infused radioactivity which was collected in 'mask' gas during the 45 min between feeds was found to be $66 \%$ (range $5^{6-8 I} \%$ ).

The mean excretion rate of methane in flatus was $0.3 \pm 0.02 \mathrm{ml} / \mathrm{min}$. The quantity of methane produced in the hind gut that was collected at the mouth $\left(M_{L H}\right.$, equation 2) in two sheep was $2 \cdot 1$ and $2 \cdot 4 \mathrm{ml} / \mathrm{min}$ as estimated using [ $\left.{ }^{14} \mathrm{C}\right]$ methane, and 2.6 and $2 \cdot 0 \mathrm{ml} / \mathrm{min}$ when $\left[{ }^{3} \mathrm{H}\right]$ methane was infused. The individual results are given in Table 3 .

Routes of excretion of methane. During $48 \mathrm{~h}$ of infusion of $\left[{ }^{3} \mathrm{H}\right] \mathrm{methane}$ into the rumen, no radioactivity was detected in the flatus, and it was concluded that transfer of methane from the rumen to the hind gut, either via the blood or by passage down the alimentary canal, was insignificant. No radioactivity was detected in the urine even after prolonged intraruminal infusions, suggesting that this route of loss was also negligible.

The mean proportions of rumen methane excreted through the lungs were found to be 4 and $6 \%$ respectively when $\left[{ }^{14} \mathrm{C}\right]-$ and $\left[{ }^{3} \mathrm{H}\right]$ methane were infused into sheep with open rumen cannulas. The remainder of the rumen methane production appeared to be lost from the gas phase presumably via eructation (Table 3 ).

As found with intraruminal infusion, no radioactivity appeared in the urine after $24 \mathrm{~h}$ of infusion into the caecum. No radioactivity appeared in rumen gases during the intracaecal infusion and it was concluded that no transfer of methane occurred between the hind gut and rumen, either along the alimentary tract or via body fluids, including blood. The two pathways of excretion of methane from the hind gut were

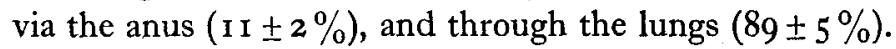

\section{DISCUSSION}

There appear to be two approaches which allow fermentation rate in the rumen of sheep and cattle to be assessed; one depends on measuring the rates of production of VFA, and the other depends on measuring dry matter disappearance and microbial protein synthesis in the rumen using animals with re-entrant cannulas in the duodenum. The latter technique is arduous, and is difficult to use on a routine basis, and for these reasons and because of ease of measurement, VFA production rates using tracer techniques have become a method of choice.

The main objective of the present work was the development of a method of measuring the rate of production in the rumen of one fermentation end-product, methane. The requirements were for a rapid, accurate and inexpensive method. These objectives appear to have been achieved.

Initial attempts to measure methane production involved infusing the isotope as a 
gas. Isotope dilution theory requires that infusion be made into, and sampling made from, the pool through which all methane produced passes, if irreversible loss rate from that pool is to be calculated. In a steady-state system where pools are linked unidirectionally, with losses from both pools but no production in the secondary pool, this secondary pool may be assumed to have the same SR as the primary pool once the system has reached a plateau SR. In the rumen methane system it is considered that the primary pool is methane in solution while the secondary pool is methane in the gaseous phase. It was found that the methane gas infused into the rumen did not mix in the pool of methane in solution in the rumen before being eructated. It was necessary therefore to prepare the isotopes in solution so that infusions could be made into the primary pool. Complete solution of radioactive methane was probably the key to obtaining meaningful results. Solution of methane was achieved by using the apparatus shown in Fig. 2. Radioactive methane solutions could be stored for considerable periods without loss.

The diffusibility of trace amounts of radioactive methane through polyethylene tubes and similar materials precluded their use, and all-metal infusion pumps and lines were necessary.

The apparatus that was eventually developed to assay methane and radioactivity was sufficiently versatile to make these measurements (I) on gas collected from the head, (2) on $30 \mathrm{ml}$ samples of gas from the rumen, or (3) on methane evolved from infusion solutions.

The early finding that methane produced in the lower digestive tract was excreted from the head as well as the anus was of invaluable help during development of the technique. This suggested that the SR of methane in gases collected from the head during intraruminal infusions might be lower than that of methane sampled directly from the rumen. That this was not so in the initial work led to recognition of the importance of the rate of infusion of water as the carrier containing the isotope. Infusion of $\left[{ }^{3} \mathrm{H}\right]$ methane into the caecum confirmed that the majority of methane produced in the lower digestive tract was excreted through the lungs. Recently, McRae, Reid, Dellow \& Wyburn (1973) reported the presence of a gas bubble in the caecum through which methane gas probably passes.

Only a small proportion of the total methane produced entered the blood (about $15 \%)$ and there was no excretion of methane in urine. The absence of detectable amounts of isotope in urine during infusions indicates that the majority of the absorbed methane is excreted at the lungs. It also suggests that although eructated gases may be inhaled (Colvin, Wheat, Rhode \& Boda, 1957; Dougherty, 196r; Hoernicke, Williams, Waldo \& Flatt, 1965) negligible quantities of methane enter the blood by this route.

A very small amount of methane was collected at the anus and this was mostly voided when the animal defaecated. Of the possible routes of excretion of methane from the animal only three routes were significant. These were: (I) eructation from the rumen, (2) absorption from the rumen and lower digestive tract and loss through the lungs, and (3) the flatus.

In some of our animals, considerable loss of methane occurred through the rumen 
cannulas. Although precautions were taken to minimize such losses, it was found by total collection studies that these losses were accounted for by the calculations used.

More methane appeared to be excreted from sheep during the feeding period than when the animal was resting, but the SR of the methane remained constant during both feeding and resting, indicating that this change was probably due to a decrease in pool size of gas in the rumen rather than an increase in methane production. The constancy of the plateau SR of methane during infusions is evidence for good mixing and the achievement of steady-state conditions. In some experiments the plateau was maintained for up to $44 \mathrm{~h}$ with little variation.

Where $\left[{ }^{14} \mathrm{C}\right]$ - and $\left[{ }^{3} \mathrm{H}\right]$ methane were compared as tracers the estimates of methane production in the same animal under the same conditions were almost identical.

Although production of methane in the lower digestive tract was only $10 \%$ of the total production in these sheep, the absorption of methane into blood and excretion via the lungs precludes estimates of rumen methane production by collection of gases from the head. However, if the relationships between methane production, VFA production, microbial growth and organic matter disappearance can be established for the rumen, and these relationships hold for the caecum, collection of methane in respirometers or from masks may be used to estimate availability of nutrients from fermentation in the whole digestive tract. If these techniques can be coupled with re-entrant cannula techniques for studying digestion in the small intestine, then the nutritional value of foods can be assessed on the basis of available nutrients.

Although the versatility of the technique is indicated by its ability to provide an estimate of methane production in the lower digestive tract as well as the rumen, that of the former is based on differences. The direct estimation of methane production in the caecum was not studied. It is unlikely that with intracaecal infusions the SR of flatus methane would represent the SR of the caecal pool of methane. A necessary prerequisite appears to be the development of a method of obtaining methane directly from the caecum. This may be possible by diffusion into $\mathrm{N}_{2}$-filled balloons positioned in the caecum.

The extent to which suppression of methane production can be achieved by various chemicals can be estimated in vivo using the above method. In addition the method may find application in research on bloat (see Bryant, Murray \& Leng, 1974).

For nutritional studies with large numbers of animals, the complex apparatus is not needed and only means of infusing and assaying radioactivity in individual rumen gas samples and of analysis of methane are required.

We are indebted to the Australian Wool Research Trust Fund, the Australian Meat Research Committee and the Rural Credits Development Fund for financial support for this project. We also wish to thank Mr R. Magnus for his engineering skill and assistance with assembly of the methane analyser equipment, and $\mathrm{Mr}$ R. Mercer who provided electronic expertise. R.M.M. was in receipt of an Australian Wool Board postgraduate scholarship and A.M.B. was supported by funds from the New Zealand Ministry of Agriculture and Fisheries. 


\section{REFERENCES}

Baldwin, R. L., Lucas, H. L. \& Cabrera, R. (1970). In Physiology of Digestion and Metabolism in the Ruminant, p. 319 [A. T. Phillipson, editor]. Newcastle upon Tyne: Oriel Press.

Bryant, A. M., Murray, R. M. \& Leng, R. A. (1974). In Reviezs in Rural Science, I. Bloat, p. 75 [R. A. Leng and J. R. McWilliam, editors]. Armidale: University of New England Press.

Colvin, H. W. Jr, Wheat, J. D., Rhode, E. A. \& Boda, J. M. (1957). F. Dairy Sci. 40, 492.

Dougherty, R. W. (196r). In Physiology of Digestion in the Ruminant, p. 79 [D. Lewis, editor]. London: Butterworths.

Grey, F. V., Weller, R. A., Pilgrim, A. F. \& Jones, G. B. (1 966). Aust. F. agric. Res. I7, 69.

Hoernicke, H., Williams, W. F., Waldo, D. R. \& Flatt, W. P. (1965). Publs Eur. Ass. Anim. Prod. no. II, p. 165 .

Hogan, J. P. \& Weston, R. H. (1970). In Physiology of Digestion and Metabolism in the Ruminant, p. 474 [A. T. Phillipson, editor]. Newcastle upon Tyne: Oriel Press.

Hungate, R. E. (1966). The Rumen and its Microbes. London: Academic Press.

Leng, R. A. (1974). In Chemistry and Biochemistry of Herbage, vol. 3, p. 8I [R. W. Bailey and G. W. Butler, editors]. New York: Academic Press.

Leng, R. A. \& Leonard, G. L. (1965). Br. F. Nutr. 19, 459.

Leng, R. A. \& Murray, R. M. (1972). Tracer Studies on Non-Protein Nitrogen for Ruminants, p. 25. Vienna: International Atomic Energy Agency.

MacRae, J. C., Reid, C. S. W., Dellow, D. W. \& Wyburn, R. S. (1973). Res. vet. Sci. 14, 78.

Royal, W. M. (1 968). Proc. Aust. Soc. Anim. Prod. 7, 450.

Weston, R. H. \& Hogan, J. P. (1968). Aust. F. agric. Res. 19, 419. 